\title{
BSF - time to change the flies
}

\section{Exordium}

The title may seem a little bizarre, and it is by no means an appeal to new political elections, in fact, it may even lead to deception since, contrary to the old political adage ("flies change but the crap is the same"), if it is true that we intend to emphasize the enormous potential of new flies, we do so because we have experimentally proven evidence that with them the "crap" also changes (or rather ends up reverting to environmental and economic benefits).

No! do not leave us hanging on to the first paragraph, because here we are not resorting to cheap populism, or praising a "universal panacea"; please grant us the benefit of the doubt and at least take a look at the rest of what we have to tell you.

In the middle of the last century, a special illegal emigrant landed in the old continent on a food supply ship: it was the "black soldier fly", which quickly disperses to the rest of the world, ${ }^{1}$ where it is naturalized in tropical and warm temperate zones, between the $45^{\circ} \mathrm{N}$ and $40{ }^{\circ} \mathrm{S}$ parallels. ${ }^{2}$

Here It has prospered, and in the Mediterranean Europe it has already been showing (in scientifically proven experimentation) a huge potential in the biological digestion of all kinds of organic leftovers.

\section{Introduction}

To make the reader more comfortable, it is convenient to affirm that the black soldier fly (better known, in the scientific bibliography of English expression, by the acronym BSF) does not even belong to the taxonomic family of the common fly, and its behavior, unlike the latter (which in many cases asserts itself as a parasite), is fundamentally symbiotic.

In addition to the evidence already given in the composting of urban and agrarian organic waste, BSF has been demonstrating (in numerous experimental and practical works) its relevant contribution to the biological digestion of organic leftovers resulting from agricultural and livestock production.

In the past decade of the last century, the use of BSF was proposed by Sheppard et $\mathrm{al}^{3}{ }^{3}$ as an efficient means of "recycling" organic leftovers by converting it in a biomass rich in protein and fat (the BSF larvae), in addition to recycled material, which constitutes an organic fertilizer for agricultural soils.

The present article focuses precisely on the decisive role of BSF in agrarian holdings under a "circular economy" regime; first, however, a brief review of BSF merits will be advisable.

\section{BSF and its merits}

The BSF (Hermetia illucens L. 1758), although belonging to the order Diptera (which justifies the common name "fly"), does not belong to the taxonomic family Muscidae, which includes the house fly (Musca domestic L.), distinguishing itself from this one, in a very evident way, by its morphology, physiology and behavior (Figure 1).

During the ephemeral adulthood (just over a week), BSF does not have a completely differentiated oral appliance, feeding exclusively on the abundant reserves accumulated during the long larval period
Volume 5 Issue 3 - 202 I

\begin{abstract}
Regina Menino,' Daniel Murta ${ }^{2,3,4}$
'Instituto Nacional de Investigação Agrária e Veterinária, IP (INIAV), Portugal

${ }^{2}$ Ento Green-Ingredient Odyssey SA, Santarém, Portugal ${ }^{3}$ CiiEM-Centro de investigação interdisciplinar Egas Moniz, Campus Universitário, Quinta da Granja Monte de Caparica, Portugal

${ }^{4}$ CIISA, Faculdade de Medicina Veterinária, Universidade de Lisboa, Portugal
\end{abstract}

Correspondence: Regina Menino, Instituto Nacional de Investigação Agrária e Veterinária, IP (INIAV), Av. da República, Quinta do Marquês, 2780-I59 Oeiras, Portugal,

Email regina.menino@iniav.pt

Received: May 14, 202 I | Published: May 27, 202 I

(more than a quarter), and therefore one of its virtues: that of not constituting a health hazard (or even a nuisance) for humans and domestic animals (Figure 2).

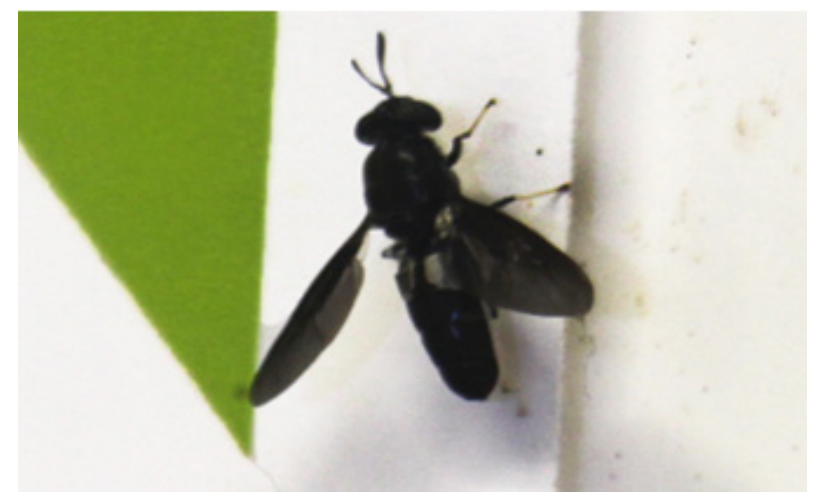

Figure I Adult Black Soldier Fly.

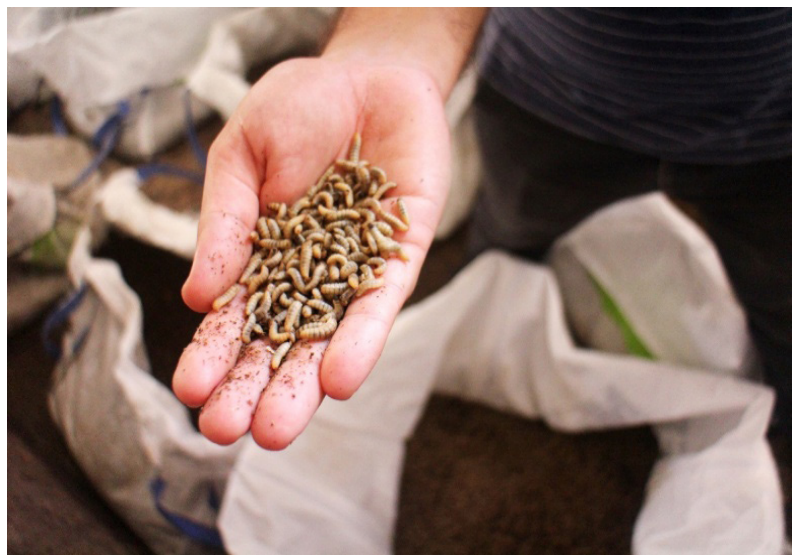

Figure 2 Black Soldier Fly larvae.

But, although this is not of minor importance, it is, nevertheless, the larval phase that is preponderant in the economy of agricultural, 
livestock and farming operations and, no less relevant, in the defense of the environment, by elimination, in the biological digestion processes, of potentially polluting organic residues, resulting from agricultural and livestock production.

BSF is provided with a very high prolificacy - more than 600 eggs per female ${ }^{4}$ - and an unparalleled voracity in the order Diptera (up to $500 \mathrm{mg}$ of fresh matter/larva/day), mainly from animal manure. As determined by Van Huis et al. ${ }^{5}$ BSF has great competence in converting residues into larval biomass, constituting a more competent composting agent than other insects, and more effective than traditional composting systems and aerobic and anaerobic digestion systems. ${ }^{6}$

In addition, BSF, in its pre-pupal phase, abandons the composted substrate, migrating to clean places (a phenomenon that is referred to in the scientific literature as self-harvesting), individualizing, without added costs, two distinct products of remarkable economic value. In particular (Figure 3):
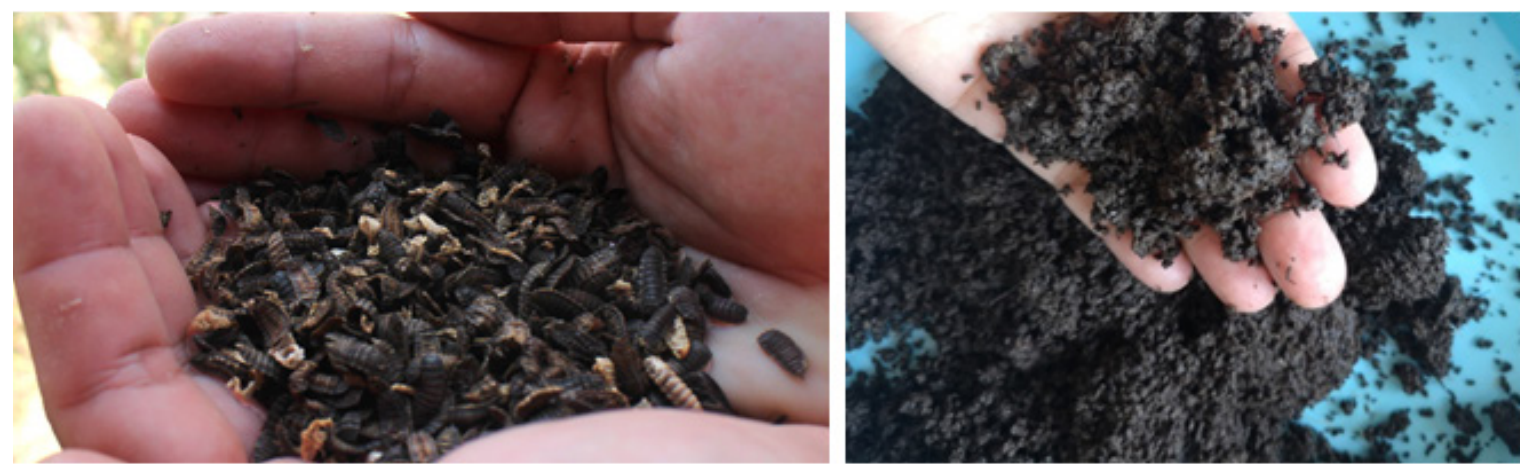

Figure 3 Pupae (on the left) and fresh frass (on the right).

i. The larvae and pupae, used both in animal feed and in the production of biodiesel, as well as in the pharmaceutical and cosmetic industry. As far as this communication is concerned, its nutritional value stands out, either when supplied in vivo in poultry and aquaculture or when included in the formulation of animal feed, competing, for this purpose, with soy and the fish offal. In particular, as far as protein is concerned, with levels on the order of $42 \%$ and an amino acid profile similar to that of constituents in animal feed, the BSF larval mass is recommended by some authors ${ }^{7}$ for inclusion in animal feed and, as stated by Gasco et al. ${ }^{8}$ the contents of lauric acid, antimicrobial peptides and chitin, in the BSF larvae, give it a high dietary value.

ii. The biologically digested after self-harvesting, which is most made up of the defecated by larvae (referred to in the English scientific bibliography as "frass"), the remainder not composted and some pupae whose larvae have not achieved self-harvesting. To this product, we attribute the acronym "CASH" (Composting After Self Harvesting), not resisting to the irony of the paradox contained in it, when comparing money in a negative eschatological relationship with the frass, and in an opposite relationship of promising pecuniary expectation.

But its merits are not exhausted here, for, as it is concluded, for example, by:

A. Van Huis et al. ${ }^{5}$-the larvae of the black soldier fly, in addition to aerating and drying the manure, process organic waste very efficiently and quickly, restricting bacterial growth and, thus, reducing the production of bad smell to a minimum;

B. Lalander et al. ${ }^{9}$-BSF composting technology is able to inactivate zoonosis mediated by bacteria, such as Salmonella spp;

C. Sheppard et al. ${ }^{3}$-BSF contributes to the control of the house fly (Musca domestica L.), limiting its egg laying, and thereby reducing its number of larvae, as verified in composting of poultry manure, in which the reduction of housefly larvae was in the order of 94 to $100 \%$;

D. Newton et al. ${ }^{10}$ - that the larvae modify the microflora of manure, potentially reducing harmful bacteria, such as Escherichia coli and Salmonella enterica.

As we all know, however, "there is no beauty without an if" and BSF (which has nothing of beauty) does not escape the adage, as, for example, the fact that in the lipid composition of the larvae there is a predominance of saturated fat acids, which is not convenient for animal feed. This situation however, can be overcome by the extraction of excess fat, through simple and inexpensive pressing, in the line proposed by St-Hilaire et al. ${ }^{11}$ This fat can be used in biodiesel production.

\section{BSF in agricultural holdings managed in accordance with circular economy system}

After the most resistant readers have given us the honor of following such an extended preamble, here we come to the main objective of the present narration, in which it is intended to highlight the decisive role of BSF in the agrarian holdings managed in accordance with a circular economy system, where maximizing activity income (by recycling) is combined with minimizing the environmental footprint.

The following diagram illustrates the role of BSF in the flow of products obtained in the process of composting organic leftovers from farming and livestock, in complete circularity, and according to the nature of the waste to be composted and the beneficiaries of it (Figure 4).

Animal production, in addition to products valued in the market (meat, milk, wool eggs, skins, etc.), should also be affirmed by the leftovers it generates - mainly manure and slurry; however, these (which can eventually be recycled directly as organic fertilizers) are not exempt from asserting their environmental footprint, in particular by smell. 


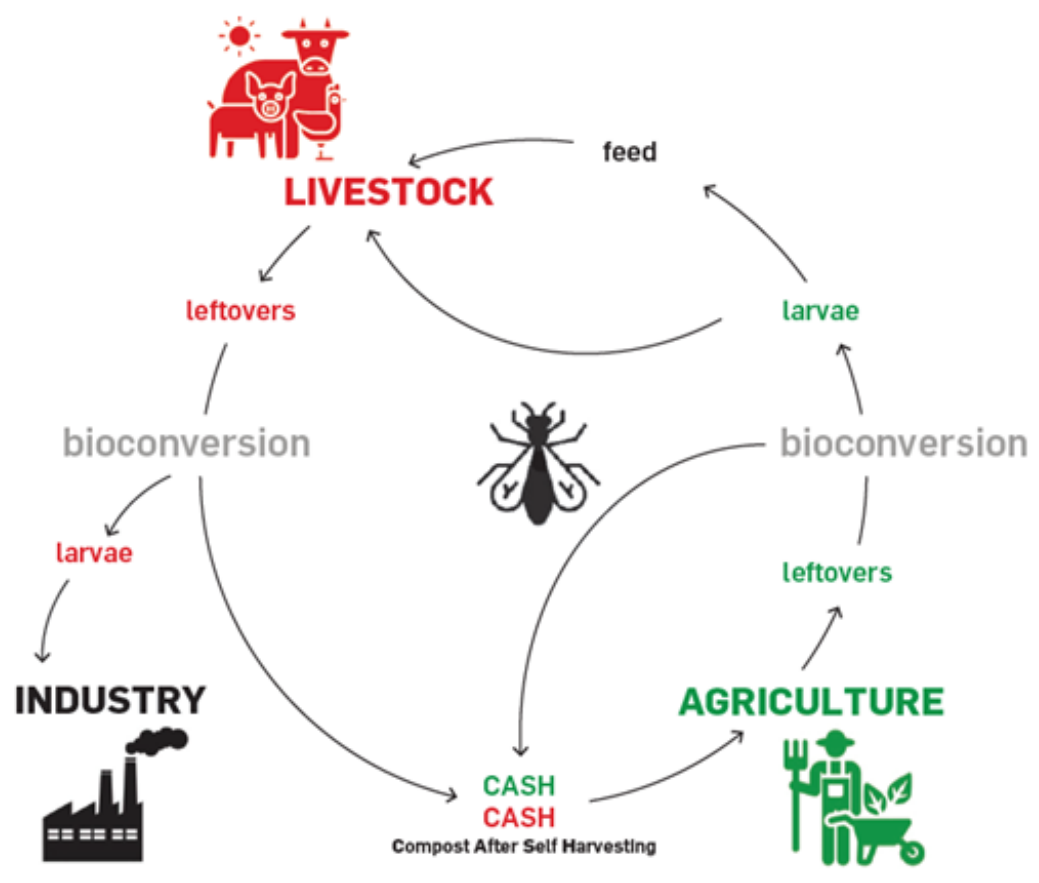

Figure 4 Role of BSF in the flow of products obtained in the process of composting organic leftovers from farming and livestock, in a context of circular economy.

This inconvenience can be mitigated by BSF biological digestion, which results in a non-polluting organic fertilizer (the "CASH"), with the added benefit of BSF pupae production, activity income and commercial value for the industry.

The nature of the leftovers to be composted, however, may limit the use of the larvae to feed animals, since the larvae fed on livestock residues can be a disease-transmitting agent, particularly bovine spongiform encephalopathy (BSE). In this situation, they should be channeled to the production of biodiesel.

The economic circularity, mediated by the BSF digestion of vegetable organic leftovers, generated in the scope of livestock feeding, is completed with the inclusion of the larvae in the feeding of the monogastric herd (as, for example, in swine, poultry, cuniculture, etc.) and fish, given legal restrictions on the inclusion of pupae in polygastric rations (such as cow, goat or sheep). Eventually, there may be convenience in the use of out sourcing, to complement the food value.

In agricultural activity, circularity is also mediated by BSF digestion of the organic leftovers generated within it, with the use of the respective "CASH" in organic soil fertilization, for all types of crops. Here too, however, it may be convenient to resort to out sourcing, particularly in what regards nitric nitrogen - scarce in any organic fertilizer and necessary for the "start-up" of crops.

In Portugal, all of this has already been demonstrated in some pot experiments, namely:

with lettuce (Lactuca sativa L.), by Esteves ${ }^{12}$ and;

with annual ryegrass (Lolium multiflorum L.), by Menino et al. ${ }^{13}$

In any of these tests, a CASH of vegetable origin was used, with a potential for fertilization not significantly lower than mixed fertilization (CASH and mineral fertilizer), with the advantage of the production economy, a significant reduction in the environmental footprint and increased soil fertility resilience.
The symbiosis between livestock and agricultural activity is achieved, on the one hand, through the inclusion of CASH of animal origin, as organic fertilizer and, on the other hand, through retribution, from the agricultural sector, through food (pastures, fodder, and other agricultural products) and, due to the larval mass developed in the biological conversion of agricultural organic waste.

In short, by reducing the inflow of resources, recycling leftovers and minimizing waste, proficiently provided by BSF (with greater speed, more hygiene, and valorization of the products it generates, than with other composting systems) the main requirements of the circular economy systems in the agrarian environment are fulfilled.

So, it looks like it's really "time to change the flies".

\section{Funding}

None.

\section{Acknowledgments}

This article was performed under the scope of the NETA project: New Strategies in Wastewater Treatment (POCI-010247-FEDER-046959) funded by PORTUGAL2020. We wish to acknowledge the design of "Figure 4." by Nuno Gusmão, from "P-06 Atelier".

\section{Conflicts of interest}

The authors have no conflict of interest for this research.

\section{References}

1. Leclercq M. A propos de Hermetia illucens (Linnaeus, 1758) (soldier fly) (diptera stratiomyidae: hermetiinae). Bull Annls Soc Belge Ent. 1997;133:275-282.

2. Diener S, Zurbrügg C, Roa Gutiérrez F, et al. Black soldier fly larvae for organic waste treatment-prospects and constraints. In: WasteSafe 2011 2nd Int. Conf. on solid waste management in the developing countries, 52-59. Khulna, Bangladesh, 2011. 
3. Sheppard DC, Newton GL, Thompson SA, et al. A value-added manure management-system using the black soldier fly. Bioresour Technol. 1994;50:275-279.

4. Tomberlin JK, Sheppard DC. Factors influencing mating and oviposition of black soldier flies (Diptera: Stratiomyidae) in a colony. J Entomol Sci. 2002;37:345-352.

5. van Huis A, van Itterbeeck J, Klunder H, et al. Edible insects - future prospects for food and feed security. FAO Forestry Paper. 171. 2013.

6. Čičková H, Newton GL, Lacy RC, et al. The use of fly larvae for organic waste treatment. Waste Management 2015;35:68-80.

7. Wang Yu-Shian, Shelomi Matan. Review of black soldier fly (Hermetia illucens) as animal feed and human food. Foods 2017;6(10):91.

8. Gasco L, Finke M, van Huis A. Can diets containing insects promote animal health? J. Insects Food Feed. 2018;4:1-4.
9. Lalander C, Diener S, Magri ME, et al. Faecal sludge management with the larvae of the black soldier fly (Hermetia illucens) -from a hygiene aspect. Science of the Total Environment. 2013;458-460:312-318.

10. Newton GL, Sheppard DC, Burtle G. Black soldier fly prepupae: a compelling alternative to fish meal and fish oil. public comment on alternative feeds for aquaculture, NOAA 15/11//2007-29/2/2008. 2008.

11. St-Hilaire S, Cranfill K, McGuire MA, et al. Fish offal recycling by the black soldier fly produces a foodstuff high in omega-3 fatty acids. $J$ World Aquac Soc. 2007;38:309-313.

12. Esteves CFM. Utilização do composto orgânico de larvas da Hermitia illucens como fertilizante em alface. Dissertação para obtenção de grau de Mestre. Instituto Superior de Agronomia (ISA), Universidade de Lisboa. 88pp. 2020.

13. Menino R, Felizes F, Castelo-Branco MA, et al. Agricultural value of Black Soldier Fly larvae frass as organic fertilizer on ryegrass. Helyion. 2021;7(1):e05855. 